\title{
AUTHORS' RESPONSE (AuGust 21, 2017) TO THE LETTER TO THE EDITOR CONCERNING THE PAPER "MORTALITY FOR CHRONIC-DEGENERATIVE DISEASES IN TUSCANY: ECOLOGICAL STUDY COMPARING NEIGHBORING AREAS WITH SUBSTANTIAL DIFFERENCES IN ENVIRONMENTAL POLLUTION"
}

Dear Editor,

Judging by their first comment, Colleagues from the Cancer Research and Prevention Institute (Istituto per lo Studio e la Prevenzione Oncologica - ISPO) are likely to misinterpret the design of our study "Mortality for chronic-degenerative diseases in Tuscany: Ecological study comparing neighboring areas with substantial differences in environmental pollution" [1,2]. One of our aim actually was "to investigate the potential links between the possible excess in mortality rates and environmental release and detection of pollutants." This clearly means to discuss the theoretical pathways possibly linking environmental pollution and mortality. We made no attempt to document a cause-effect relationship between those factors (a link that could not be investigated by an ecological study). This is also clearly stated in the Conclusion where we wrote "it is not possible to establish a causal link between environmental pollution and increased mortality. Alternative causes could therefore contribute to (or even totally explain) the reported differences in mortality for cardiovascular and neurodegenerative diseases."
The Table 1 actually shows standardized mortality rates (SMR); the wrong value of SMR for cerebrovascular diseases was the result of a mere clerical error. We have attached the Table 1 as corrigendum.

As stated in the Material and Methods, data was obtained by the Regional Mortality Registry (Registro di Mortalità Regionale - RMR), as elaborated by the ISPO. Reference population was the European standard population elaborated by Eurostat in 1976, that was used in the above-mentioned RMR available at the moment of our analysis. We are aware of a later release of the RMR, using an updated European standard population (2013), giving a relatively lower weight to mortality in the elderly and a higher weight to early mortality. This update was released only after completion of the study. We are comforted to observe that, in the Table attached to the letter, the same mortality excesses are observed when the updated European reference population is used. With regard to the questions about the International Statistical Classification of Diseases and Related Health Problems, its 10th revision (ICD 10) defining the coding for ischemic heart diseases, our intention was to separate 
Table 1. Standardized mortality rates (SMR) in Tuscany, Bassa Val di Cecina, Rosignano and Cecina, Italy, in 2001-2010 for the diseases showing significant excess in comparison to the reference population

\begin{tabular}{|c|c|c|c|c|c|}
\hline \multirow[b]{2}{*}{$\begin{array}{l}\text { Respondents } \\
\text { and area }\end{array}$} & \multicolumn{5}{|c|}{$\begin{array}{l}\text { Standardized mortality rate } \\
(95 \% \mathrm{CI})\end{array}$} \\
\hline & $\begin{array}{l}\text { mesothelioma } \\
\quad \text { (C45) }\end{array}$ & $\begin{array}{c}\text { ischemic heart } \\
\text { diseases } \\
(\mathrm{I} 20-\mathrm{I} 25)\end{array}$ & $\begin{array}{c}\text { other forms of } \\
\text { ischemic heart } \\
\text { diseases } \\
(\mathrm{I} 20, \mathrm{I} 22-\mathrm{I} 25)\end{array}$ & $\begin{array}{c}\text { cerebrovascular } \\
\text { diseases } \\
\text { (I60-I69) }\end{array}$ & $\begin{array}{c}\text { Alzheimer and other } \\
\text { degenerative diseases } \\
\text { of nervous system } \\
\text { (G30-G31) }\end{array}$ \\
\hline \multicolumn{6}{|l|}{ Total } \\
\hline Tuscany (reference) & $1.21(1.12-1.30)$ & $55.34(54.81-55.87)$ & $30.96(30.59-31.33)$ & $53.32(52.84-53.8)$ & $7.97(7.79-8.15)$ \\
\hline Bassa Val di Cecina & $2.51(1.66-3.36)$ & $\mathbf{6 5 . 7 2}(62.03-69.41)$ & $40.13(37.4-42.86)$ & $\mathbf{5 7 . 1 6}(53.85-60.47)$ & $\mathbf{9 . 6 6}(8.37-10.95)$ \\
\hline Rosignano & $\mathbf{3 . 6 9}(2.11-5.27)$ & $\mathbf{6 2 . 4 0}(56.84-67.96)$ & $\mathbf{3 6 . 4 7}(32.46-40.48)$ & $\mathbf{6 0 . 2 2}(54.9-65.54)$ & $\mathbf{1 2 . 3 6} *(10.1-14.62)$ \\
\hline Cecina & $1.93(0.59-3.27)$ & $72.95(66.22-79.68)$ & $45.31(40.36-50.26)$ & $55.13(49.63-60.63)$ & 7.57 (5.55-9.59) \\
\hline \multicolumn{6}{|l|}{ Males } \\
\hline Tuscany (reference) & $2.11(1.93-2.29)$ & $79.04(78.03-80.05)$ & $43.31(42.59-44.03)$ & $\underline{59.26(58.42-60.10)}$ & $7.41(7.12-7.7)$ \\
\hline Bassa Val di Cecina & $4.64(2.9-6.38)$ & $\mathbf{8 8 . 3 3}(81.49-95.17)$ & $\mathbf{5 2 . 4 6}(47.38-57.54)$ & $63.80(58.16-69.44)$ & $8.38(6.43-10.33)$ \\
\hline Rosignano & $6.87(3.59-10.15)$ & 83.24 (72.94-93.54) & $46.97(39.56-54.38)$ & $66.67(57.71-75.63)$ & $10.55(7.2-13.9)$ \\
\hline Cecina & $3.64(0.87-6.41)$ & $99.01(86.24-111.8)$ & $\mathbf{5 8 . 5 9}(49.16-68.02)$ & $61.14(51.58-70.7)$ & $6.32(3.26-9.38)$ \\
\hline \multicolumn{6}{|l|}{ Females } \\
\hline Tuscany (reference) & $0.49(0.41-0.57)$ & $37.77(37.24-38.3)$ & $22.42(22.04-22.8)$ & $48.59(48.01-49.17)$ & $8.20(7.97-8.43)$ \\
\hline Bassa Val di Cecina & $0.63(0.21-1.05)$ & $\mathbf{4 8 . 4 3}(44.59-52.27)$ & $31.51(28.56-34.46)$ & $51.54(47.59-55.49)$ & $\mathbf{1 0 . 5 6}(8.81-12.31)$ \\
\hline Rosignano & $0.94(0.18-1.7)$ & $\mathbf{4 6 . 0 9}(40.4-51.78)$ & $28.83(24.5-33.16)$ & $54.60(48.21-60.99)$ & $\mathbf{1 3 . 6 5}(10.56-16.74)$ \\
\hline Cecina & $0.52(0-1.27)$ & $\mathbf{5 4 . 3 8}(47.39-61.37)$ & $\mathbf{3 6 . 8}(31.37-42.23)$ & $50.66(43.99-57.33)$ & $8.21(5.55-10.87)$ \\
\hline
\end{tabular}

ICD-10 - International Statistical Classification of Diseases and Related Health Problems, 10th revision; CI - confidence interval.

$* p<0.05$ as compared to Cecina.

Significant excess in mortality rates as compared to Tuscany (reference) are bolded.

Underlined are corrections made by authors in response to the letter to the editor.

mortality due to myocardial infarction (MI) from the one due to the other ischemic heart diseases. This is an usual procedure when dealing with ischemic heart diseases, since acute MI prognosis is strictly tied to the existence and effectiveness of a territorial emergency services (MI network). The inherent unevenness of these networks makes MI mortality hardly comparable among diverse areas.

Coding for Alzheimer and other degenerative diseases of nervous system was kept separated by other forms of dementia (F01-F03) (as reported in the updated RMR elaborated by the ISPO available at the time of analysis); mortality rates for all these neurological degenerative diseases were evaluated. Coding for mesothelioma included all localizations (even if pleural forms were largely prevailing). As our study group includes clinical cardiologists, we are absolutely aware that mortality for ischemic heart diseases is heavily affected by differences in performance of acute illnesses care and, even more, by differences in behavioral risk factors (smoke, dietary habits, physical inactivity). In the paper, we clearly recognize that second level studies, aiming to clarify the possible influence of these potentially confounding factors, are mandatory. As far as the question about statistical methods is concerned, we would like to underline that evaluating the overlap between the upper and lower bounds of 2 confidence intervals ( $95 \%$ CIs) of 2 rates does not always tell whether the 2 rates 
are statistically different in terms of a $p<0.05$. In order to formally calculate a p-value for this difference between rates, we used the Chi ${ }^{2}$ test to quantify the extent to which the difference of mortality rates between areas was statistically significant at an $\alpha$ level of 0.05 . We then assessed the $95 \%$ CI of each mortality rate to report the degree of confidence of these values considering the actual sample size of each area.

The problem of the possible non-occupational exposure to asbestos is not only a matter of epidemiology but also (and maybe rather) a matter of environmental detection of asbestos contamination. No reliable data on this topic is available for the area of the study. Data provided in 2007 by the Regional Agency for Environment (Agenzia Regionale per la Protezione Ambientale della Toscana-ARPAT) is limited to the report of the presence of asbestos in public buildings and industrial plants, bearing no indication of the amount of asbestos in each site. No information is provided about the presence of asbestos outside these sites. Without such data, the origin of the cases of mesothelioma arising in non-occupational exposed subjects cannot be studied thoroughly.

We would like to conclude our reply by thanking the Colleagues for their comments and clarification queries. Results of our paper were already strongly grounded by the inner coherence of observing the presence, in the studied area, of both environmental pollution and mortality excesses due to diseases pathophysiologically linked to the detected pollutants. The contribution of the Colleagues from the ISPO, providing both a careful methodological scrutiny and new data about standardized mortality ratios calculated with updated standard European population, undoubtedly reinforces our results.

Key words:

Heavy metals, Particulate matters, Environmental pollution, Mesothelioma, Ischemic heart disease, Neurologic degenerative diseases

\section{REFERENCES}

1. Chellini E, Martini A, Giovannetti L, Barchielli A. Letter to the editor (July 28, 2017) concerning the paper "Mortality for chronic-degenerative diseases in Tuscany: Ecological study comparing neighboring areas with substantial difference in environmental pollution." Int J Occup Med Environ Health. 2018;31(4):543-6, https://doi.org/10.13075/ijomeh. 1896.01246 .

2. Marabotti C, Piaggi P, Scarsi P, Venturini E, Cecchi R, Pingitore A. Mortality for chronic-degenerative diseases in Tuscany: Ecological study comparing neighboring areas with substantial differences in environmental pollution. Int J Occup Med Environ Health. 2017;30(4):641-53, https://doi. org/10.13075/ijomeh.1896.00972.

Claudio Marabotti ${ }^{1,2}$, Paolo Piaggi ${ }^{3,4}$, Paolo Scarsi ${ }^{5}$, Elio Venturini ${ }^{1}$, Romina Cecchi ${ }^{1}$, and Alessandro Pingitore ${ }^{2}$

${ }^{1}$ Bassa Val di Cecina Hospital, Cecina (LI), Italy Cardiovascular and Coronary Care Unit ${ }^{2}$ National Research Council (CNR), Pisa, Italy Institute of Clinical Physiology

${ }^{3}$ National Institutes of Health, Phoenix, Arizona, USA Phoenix Epidemiology and Clinical Research Branch, National Institute of Diabetes and Digestive and Kidney Diseases

${ }^{4}$ University of Pisa, Pisa, Italy Department of Endocrinology and Metabolism ${ }^{5}$ National Research Council (CNR), Pisa, Italy Institute of Geosciences and Earth Resources

Corresponding author: Claudio Marabotti Bassa Val di Cecina Hospital, Cardiovascular and Coronary Care Unit via Montanara 1, 57023 Cecina (LI), Italy (e-mail: c.marabotti@alice.it)

This work is available in Open Access model and licensed under a Creative Commons Attribution-NonCommercial 3.0 Poland License - http://creativecommons.org/ licenses/by-nc/3.0/pl/deed.en. 